\title{
The Role of the Medial Prefrontal Cortex (Cingulate Gyrus) in the Regulation of Hypothalamic-Pituitary-Adrenal Responses to Stress
}

\author{
Diane Diorio, Victor Viau, and Michael J. Meaney \\ Developmental Neuroendocrinology Laboratory, Douglas Hospital Research Center, Departments of Psychiatry, and \\ Neurology and Neurosurgery, McGill University, Montréal, Canada H4H 1R3
}

In the studies reported here we have examined the role of the medial prefrontal cortex (MpFC) in regulating hypothalamic-pituitary-adrenal (HPA) activity under basal and stressful conditions. In preliminary studies we characterized corticosteroid receptor binding in the rat MpFC. The results revealed high-affinity $\left(K_{d} \sim 1 \mathrm{~nm}\right)$ binding with a moderate capacity $(42.9 \pm 3 \mathrm{fmol} / \mathrm{mg})$ for ${ }^{3} \mathrm{H}$-aldosterone (with a 50 fold excess of cold RU28362; mineralocorticoid receptor) and high-affinity $\left(K_{d} \sim 0.5-1.0 \mathrm{~nm}\right)$ binding with higher capacity (183.2 $\pm 22 \mathrm{fmol} / \mathrm{mg}$ ) for ${ }^{3} \mathrm{H}-\mathrm{RU} 28362$ (glucocorticoid receptor). Lesions of the MpFC (cingulate gyrus) significantly increased plasma levels of both adrenocorticotropin (ACTH) and corticosterone (CORT) in response to a $20 \mathrm{~min}$ restraint stress. The same lesions had no effect on hormone levels following a $\mathbf{2 . 5}$ min exposure to ether. Implants of crystalline CORT into the same region of the MpFC produced a significant decrease in plasma levels of both ACTH and CORT with restraint stress, but again, there was no effect with ether stress. Neither MpFC lesions nor CORT implants had any consistent effect on A.M. or P.M. levels of plasma ACTH or CORT. Manipulations of MpFC function were not associated with changes in the clearance rate for CORT or in corticosteroid receptor densities in the pituitary, hypothalamus, hippocampus, or amygdala.

Taken together, these findings suggest that MpFC is a target site for the negative-feedback effects of glucocorticoids on stress-induced HPA activity, and that this effect is dependent upon the nature of the stress.

IKey words: medial prefrontal cortex, cingulate gyrus, rat, glucocorticoids, adrenocorticotropin, corticosteroid receptors, stress]

The hypothalamic-pituitary-adrenal (HPA) response to stress comprises a major element of the organism's reaction to stimuli that threaten homeostasis (i.e., stress). The characterization of corticotropin-releasing hormone (CRH) by Vale's group in 1981 (e.g., Rivier et al., 1982) provided the basis for a wealth of studies on the transduction of neural signals into the activation

Received Sept. 2, 1992; revised Aug. 18, 1993; accepted Mar. 23, 1993.

This work was supported by rescarch grants from the Mcdical Research Council of Canada (MRCC) and le Fonds de Recherche en Sante du Quebec to M.J.M. who is a University Research Fellow of the Natural Sciences and Engineering Research Council and an MRCC Scientist. D.D. was supported by a graduate fellowship from the FCAR (Québec).

Correspondence should be addressed to Michael J. Meaney, Developmental Neuroendocrinology Laboratory, Douglas Hospital Research Centre, 6875 Boulevard LaSalle, Montréal, Québec H4H IR3, Canada.

Copyright (C) 1993 Society for Neuroscience $0270-6474 / 93 / 133839-09 \$ 05.00 / 0$ of the pituitary-adrenal system. These studies have demonstrated that the activation of pituitary adrenocorticotropin (ACTH) release is mediated by the secretion of $\mathrm{CRH}$, and often cosecretagogues such as arginine vasopressin (AVP) and oxytocin, from neurons with axon terminals in the median eminence of the hypophysial portal system (see Antoni, 1986; Gibbs, 1986; Rivier and Plotsky, 1986; Plotsky, 1987). For the most part, these axons arise from peptidergic neurons in the paraventricular nucleus of the hypothalamus (PVN; Swanson et al., 1987).

In addition, there is now a much better understanding of the processes by which the adrenal glucocorticoids feed back onto pituitary and brain sites to inhibit stress-induced HPA activity (i.e., glucocorticoid negative-feedback). The results from a series of studies from Dallman's laboratory, including studies on the diurnal variation in glucocorticoid control of stress-induced ACTH release, have suggested that the primary sites mediating glucocorticoid negative-feedback inhibition are distal to the CRH/AVP neurons of the PVN (see Dallman et al., in press). Thus, perhaps one of the most interesting features to emerge from the more recent studies on this topic is the importance of extrahypothalamic sites as targets for the negative-feedback actions of circulating glucocorticoids. Most notable among these regions is the hippocampus (see Sapolsky et al., 1984, 1986; McEwen et al., 1986; Herman et al., 1989; Jacobson and Sapolsky, 1991). In the rat, this structure contains both mineralocorticoid and glucocorticoid receptors that bind with high affinity to corticosterone (CORT; see Reul and De Kloet, 1985; McEwen et al., 1986; Funder and Sheppard, 1987). Studies using antagonists of the two receptor sites have implicated both receptors in the negative-feedback actions of CORT (Ratka et al., 1989; Bradbury et al., 1991).

In addition to the hippocampus, there is evidence for a high density of corticosteroid receptors in the cerebral cortex of both the rat (see Meaney and Aitken, 1985; McEwen et al., 1986) and human (Sarrieau et al., 1988). Indeed, the original autoradiographic studies from the McEwen lab (see McEwen et al., 1986 , for a review) indicated a high retention of ${ }^{3} \mathrm{H}-\mathrm{CORT}$ in the cortex, particularly in the medial regions of the frontal cortex. Feldman and Conforti (1985) found that electrical stimulation of the frontal cortex altered plasma levels of CORT in the rat. Herman et al. (1989) recently reported that cortical lesions result in increased CRH and AVP mRNA levels in the PVN. Moreover, certain states associated with increased glucocorticoid production, such as anxiety and depression, are known to be associated with frontal cortex dysfunction (see Gray, 1982). Finally, although rather little is known about the neuroendocrine role of the frontal cortex, the importance of this 
structure in behavioral, emotional, and autonomic responses to stress has been well established (for reviews, see Gray, 1982; LeDoux, 1987).

In the studies reported here we examined the role of the medial prefrontal cortex (MpFC) in the regulation of HPA function under both resting and stressful conditions. The results suggest that the MpFC can influence the HPA response to stress and that this effect depends upon the nature of the stress.

\section{Materials and Methods}

Animals. Male Long-Evans hooded rats obtained from Charles River Canada (St. Constant, Québec) and weighing approximately $350 \mathrm{gm}$ were used in these studies. The animals were housed at the Research Center for at least 1 month prior to testing. The animals were provided with food and water ad libitum, and housed in an animal facility maintained on a $12 \mathrm{hr}: 12 \mathrm{hr}$ light/dark cycle (lights off at $2000 \mathrm{hr}$ ). All animals were 4-5 months of age at the time of testing.

Four days prior to testing animals were implanted with indwelling jugular catheters under Metophane anesthesia. Catheterized animals were single housed for the remainder of the study. Bilateral adrenalectomies were performed under Metophane anesthesia and adrenalectomized animals were maintained on $0.9 \%$ saline as drinking water. All procedures were conducted in accordance with the guidelines of the Canadian Council on Animal Care and the McGill University Animal Care Committee.

Lesion studies. Bilateral thermal lesions of the medial prefrontal cortex (medial prefrontal cortex/cingulate gyrus) were made under pentobarbital (Nembutal) anesthesia with the electrode tip of a radiofrequency lesion generator (Radionics Inc., Burlington, MA) maintained at $55^{\circ} \mathrm{C}$. for $1 \mathrm{~min}$. The following stereotaxic coordinates (Paxinos and Watson, 1982) were used with bregma as the anterior-posterior reference to the dura: AP $13.0 \mathrm{~mm}$, ventral $-4.0 \mathrm{~mm}$, and $0.8 \mathrm{~mm}$ from the midline. Sham-operated animals received the same treatment as the lesioned animals, but the electrode tip was simply lowered. Animals were tested 2 weeks following lesions. Following testing the animals were perfused under deep anesthesia, the brains were removed and sectioned, and the relevant sections were Nissl stained for verification of the location and estimation of the minimal/maximal extent of the lesion.

Steroid implants. Cannulas (24 gauge) containing pure crystalline CORT (Sigma, St. Louis, MO) were implanted bilaterally into the MpFC under pentobarbital anesthesia using the same stereotaxic coordinates as described for the lesion studies. Cannulas, containing $150 \mu \mathrm{g}$ of CORT, were tightly secured to the skull with dental acrylic. Control animals received the same surgical procedure and were implanted with cannulas containing cholesterol. Testing was performed $4 \mathrm{~d}$ following surgery.

Following testing, the cannulas werc removed and weighed, and in each case approximately $80 \%$ of the CORT remained in the cannula. Brains were processed as described above in order to verify the placement of the cannula. In order to determine the diffusion of the steroid away from the cannula tip, a separate group of animals were implanted unilaterally with cannula containing ${ }^{3} \mathrm{H}-\mathrm{CORT}$ plus cold CORT using a procedure previously described by Meaney and McEwen (1986). The radiolabeled steroid was put into solution in ethanol with cold CORT, dried under nitrogen, and tapped into the cannula $(\sim 150 \mu \mathrm{g}$ CORT per cannula) using the same procedure as described above. Four days following surgery the animals were killed and the degree of steroid diffusion was assessed in microdissected tissue samples. Briefly, animals were decapitated under anesthesia and brains frozen on dry ice. The brains were sectioned (300 $\mu \mathrm{m}$ thickness) and 1 -mm-diameter areas (i.e., punches) in the vicinity of the cannula tip were removed using the atlas of Palkovits and Brownstein (1988). Steroid was extracted from dispersed tissue samples with $200 \mu \mathrm{l}$ of ethanol at $37^{\circ} \mathrm{C}$. Following extraction, the samples were centrifuged at $20,000 \times g$ and $100 \mu$ laliquots of the supernatant/extract were then counted in $5 \mathrm{ml}$ of scintillation cocktail (Liquiscent, National Diagnostics, Sommervile, NJ) using an LKB scintillation counter at $40 \%$ efficiency. The remaining pellet was resuspended in $0.1 \mathrm{~N} \mathrm{NaOH}$ and protein concentrations were determined using the method of Bradford (1976). The results were expressed as $\mathrm{cpm} / \mathrm{mg}$ protein.

Blood sampling under basal and stressful conditions. Basal CORT levels over the diurnal cycle were measured as previously described (e.g., Meaney et al., 1989). Briefly, blood samples $(\sim 50 \mu \mathrm{l})$ were taken from the tail vein at six time points over a $24 \mathrm{hr}$ cycle. Samples were taken in heparinized lubes, placed on ice, centrifuged, and stored at $-30^{\circ} \mathrm{C}$ until assayed. Blood samples $(250 \mu \mathrm{l})$ for ACTH determination were taken at a separate time, $2 \mathrm{hr}$ following the time of lights on (1000 $\mathrm{hr}$, light phase) and off ( $2200 \mathrm{hr}$, dark phase) in tubes containing EDTA and trasylol, centrifuged, stored at $-80^{\circ} \mathrm{C}$, and assayed for plasma ACTH within 1 week of the experiment (note that because of the larger sample required, sampling for ACTH levels occurred only at two time points). In all cases, animals were sampled less than $20 \mathrm{sec}$ following their removal from their home cages in order to obtain valid estimates of basal hormone levels.

Restraint stress was performed between 1300 and $1500 \mathrm{hr}$ using tubular, plastic restrainers lined with foam rubber. The animals were placed into the restrainers for a 20 min period. A blood sample $(\sim 150$ $\mu$ l) was taken immediately before the animal was placed into the restrainer, and this sample was used as an estimate of basal hormone levels prior to stress. Blood samples $(\sim 150 \mu$ l) were then taken from the same animals via a jugular catheter at various times during and following the termination of the stressor. The time 0 point was taken just before releasing the animals from the restrainers (i.e., $0 \mathrm{~min}$ following termination of the stressor) and represents the peak stress value (see Meaney et al., 1989). For ether stress, animals were maintained for $2.5 \mathrm{~min}$ in a glass container lined with absorbent paper soaked with ether. Samples were collected via a jugular catheter immediately following ether exposure and at various times thereafter. Blood samples were processed as described above.

Radioimmunoassays. Plasma CORT was measured using the radioimmunoassay of Krey et al. (1975) with a highly specific CORT antiserum (B3-163, Endocrine Sciences, Tarzana, CA) and ${ }^{3} \mathrm{H}$-CORT (101.0 $\mu \mathrm{Ci} / \mathrm{mmol}$; New England Nuclear, Boston, MA) as tracer. The minimum level of detection with the assay is $1 \mathrm{ng} / \mathrm{ml}$. The antiserum cross-reacts slightly with desoxycorticosterone $(\sim 4 \%)$ but not with cortisol $(<1 \%)$. The intra- and interassay coefficients of variation are $8.9 \%$ and $11.2 \%$, respectively. Plasma ACTH was measured using the radioimmunoassay kit of ICN Biomedicals (Carson, CA) with ${ }^{125} \mathrm{I}-\mathrm{ACTH}$ as tracer. The ACTH antibody cross-reacts $100 \%$ with $\mathrm{ACTH}_{1.39}$ and $\mathrm{ACTH}_{1.24}$, but less than $1 \%$ with $\beta$-endorphin, $\alpha$ - and $\beta$-melanocyte-stimulating hormone (MSH), and $\alpha$ - and $\beta$-lipotropin. The intra- and intcrassay coefficients of variation are $6.0 \%$ and $10.7 \%$, respectively. The minimal detectable level of plasma ACTH is about $10 \mathrm{pg} / \mathrm{ml}$.

Corticosteroid receptor binding assays. Animals were killed by decapitation 12-14 hr following adrenalectomy, a time period that allows for the clearance of the endogenous steroid. Following decapitation the brain was quickly removed and placed on ice, and the prefrontal cortex, hippocampus, hypothalamus, amygdala, and/or pituitary were dissected, frozen on dry ice, and stored at $-80^{\circ} \mathrm{C}$ until assayed. The tissue was homogenized in $30 \mathrm{~mm}$ Tris, $1 \mathrm{~mm}$ EDTA, $10 \mathrm{~mm}$ sodium molybdate, $10 \% \mathrm{v} / \mathrm{v}$ glycerol, and $1 \mathrm{~mm}$ dithiothreitol (TEDGM; $\mathrm{pH}$ adjusted to 7.4). The homogenate was centrifuged at $2^{\circ} \mathrm{C}$ for $60 \mathrm{~min}$ at $105,000 \times$ $g$ in a Beckman L8-80 ultracentrifuge. For determination of glucocorticoid receptor binding capacity, aliquots $(150 \mu \mathrm{l})$ of the soluble fraction were incubated with $100 \mu \mathrm{l}$ aliquots of TEDGM containing ${ }^{3}$ II-RU 28362 (77.9 Ci/mmol; New England Nuclear, Boston, MA) in a concentration range of $0.1-10 \mathrm{nM}$ at $0-4^{\circ} \mathrm{C}$ for $20-22 \mathrm{hr}$ (a time that has been shown to be sufficient for maximal exchange to occur and during which binding is stable; see Kalimi and Hubbard, 1983; Reul and De Kloet, 1985; Reul et al., 1987a,b). We routinely use exchange conditions in binding experiments in order to minimize the effects of any residual steroid in the tissue. Nonspecific binding was determined in parallel incubations containing a 500-fold excess of unlabeled CORT. RU 28362 has been shown to bind selectively to the glucocorticoid receptor, showing very little affinity for the mineralocorticoid receptor (Philibert and Moguilewsky, 1983; Coirini et al., 1985). For single point assays aliquots of the soluble fraction were incubated with a saturating $8 \mathrm{~nm}$ concentration of ${ }^{3} \mathrm{H}-\mathrm{RU} 28362$.

Mineralocorticoid receptor binding capacity in the MpFC and the hippocampus was measured using ${ }^{3} \mathrm{H}$-aldosterone with a 50 -fold excess of cold RU28362 in order to preclude radioligand binding to glucocorticoid receptor sites. Aliquots $(150 \mu \mathrm{l})$ of soluble fractions prepared from hippocampal tissue were incubated at $0-4^{\circ} \mathrm{C}$ for $20-22 \mathrm{hr}$ in the presence of a concentration range of ${ }^{3} \mathrm{H}$-aldosterone $(82.0 \mu \mathrm{Ci} / \mathrm{mmol}$; New England Nuclear, Boston, MA) of 0.3-15 nM in TEDGM. Nonspecific binding was determined in parallel incubations containing a 500 -fold excess of unlabeled CORT.

Sephadex LH-20 columns $(4 \times 1 \mathrm{~cm})$, made from disposable pipette tips and equilibrated with TEDGM, were used to separate bound from 


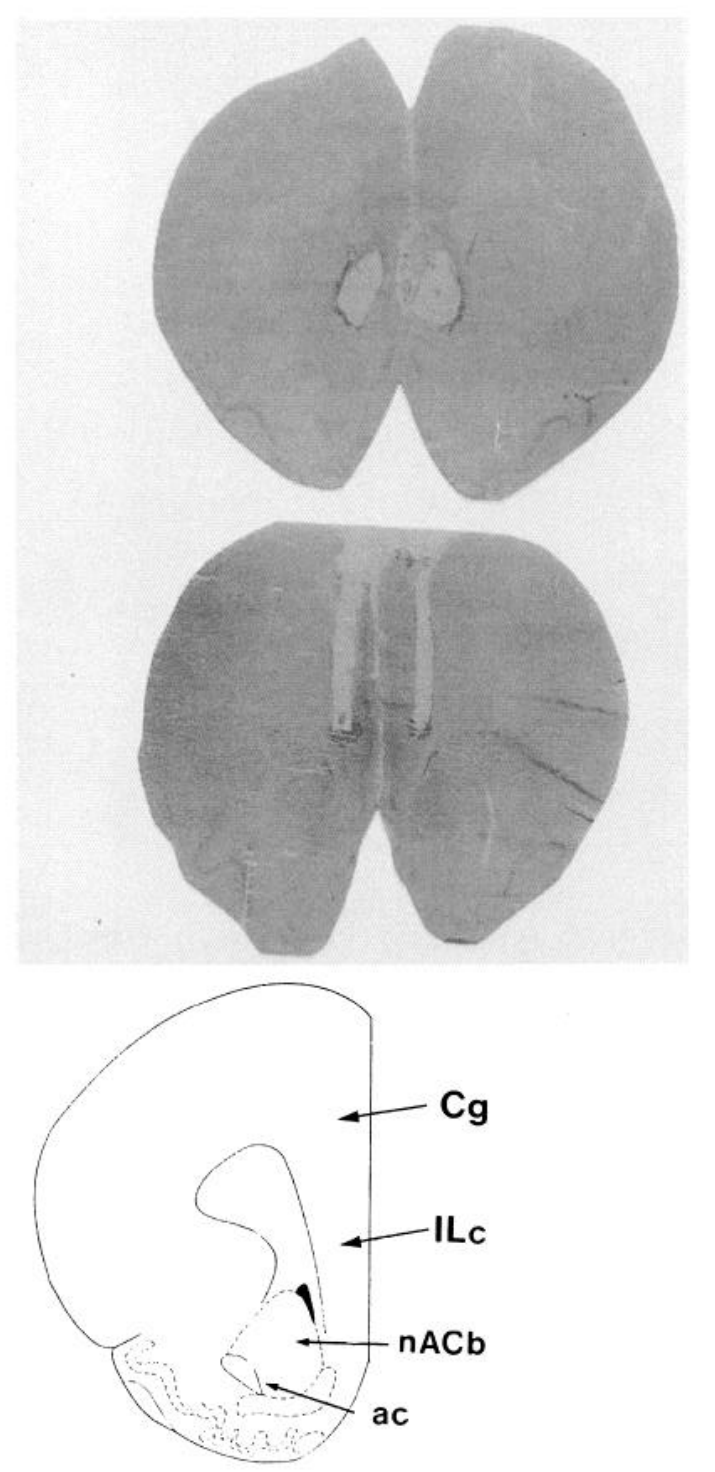

Figure 1. Shown are photomicrographs of representative lesions (top) and cannulas placements (middle), along with a schematic guide to the relevant sections. The maximal extent of the lesion is depict in the above section and characterizes the damage that includes primarily the cingulate cortex (area $3 ; \mathrm{Cg}$ ) and the infralimbic cortex $(I L c)$. The dorsal portion of the dorsal peduncular cortex was also damaged, although in no cases was this nuclei entirely damaged. The damage extended anteriorly into the cingulate cortex, without involving any other regions. At the more posterior extent, the lesion involved the indusium griseum and the cingulate cortex (area 2). Animals showing damage involving other structures or with damage that was not bilateral were excluded from the study. The cannula placement centered on the ventral portion of the cingulate gyrus (area 3 ) and the dorsal portion of the infralimbic cortex. The $1 \mathrm{~mm}$ region above the cannula tip was the only region outside of the target area of the cannula tip to show levels of ${ }^{3} \mathrm{H}-\mathrm{CORT}$ that were significantly higher than background (see Results and Fig. 2). This area included only the dorsal portion of the cingulate gyrus. Data from animals that do not show bilateral implants in the same region were excluded. Analysis was based on the atlas of Paxinos and Watson (1982).

unbound steroid. Following the incubation, $100 \mu \mathrm{l}$ of the incubates were washed into the columns with $100 \mu \mathrm{l}$ of TEDGM. The columns were eluted $30 \mathrm{~min}$ later with $500 \mu \mathrm{l}$ of TEDGM into minivials, which were then filled with $5 \mathrm{ml}$ of Liquiscent (National Diagnostics, Somerville, $\mathrm{NJ}$ ), and counted in a Packard scintillation counter at $40 \%$ efficiency. Protein content was determined using the method of Bradford (1976) and the results were expressed as femtomoles $(\mathrm{fmol}) / \mathrm{mg}$ protein specific

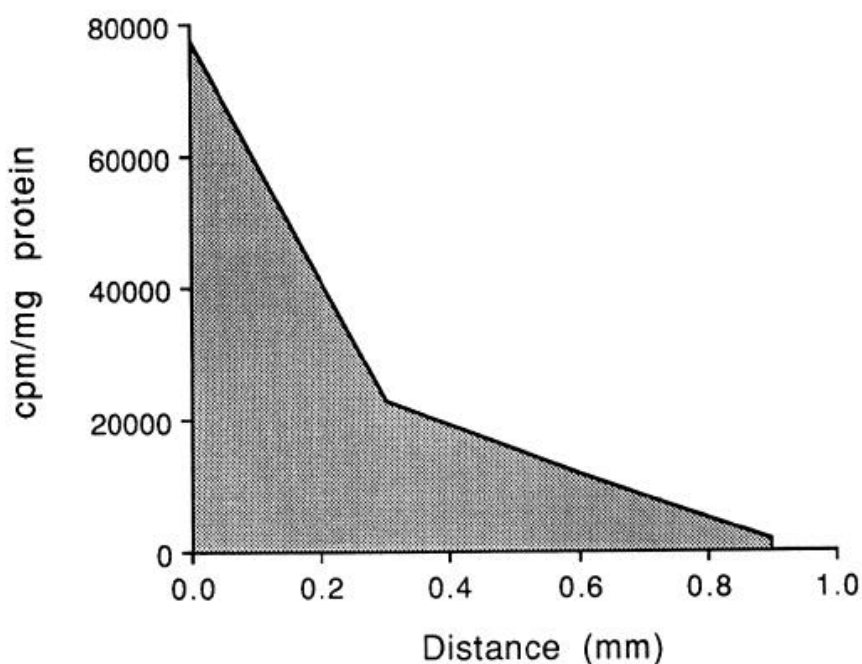

Figure 2. The graph indicates the posterior diffusion (in millimeters) of ${ }^{3} \mathrm{H}$-CORT $(\mathrm{cpm} / \mathrm{mg}$ protein) from the site of the cannula tip determined in serial $300 \mu \mathrm{M}$ sections within the $1 \mathrm{~mm}$ target region of the cannula tip (the $0 \mathrm{~mm}$ point indicates the site of the cannula tip).

binding. Protein concentrations ranged from 300 to $500 \mu \mathrm{g} / \mathrm{ml}$ for the brain tissue assays and from 200 to $300 \mu \mathrm{g} / \mathrm{ml}$ for the pituitary assays.

Statistical analysis. Statistical analysis of data from multiple groups was performed using analysis of variance with Tukey post hoc tests where appropriate. Comparisons involving two means were performed using unpaired $t$ tests. The results of the saturation experiments were analyzed using Scatchard plot analysis (Scatchard, 1949) in order to derive affinity constants $\left(K_{d}\right)$ and estimates of binding capacity $\left(B_{\max }\right)$.

\section{Results}

Histology. The maximal extent of the damage associated with the radiofrequency lesions was assessed in Nissl-stained sections and is summarized in Figure 1. The lesions were centered on the cingulate gyrus region of the $\mathrm{MpFC}$, with some damage extending into the infralimbic region.

The results of the steroid diffusion study are presented schematically in Figures 1 and 2. Steroid extract from plasma showed that radioactivity levels were not significantly different from background. Likewise, we found no evidence for radiolabeled CORT in pituitary extracts. The distribution of the radioactivity in the brain was largely confined to a $1 \mathrm{~mm}$ region surrounding the target site of the cannula tip (see Fig. 2). Outside of this region, radioactivity levels generally did not significantly exceed background. The only exception was in the $1 \mathrm{~mm}$ punch directly above the location of the cannula tip. However, while ${ }^{3} \mathrm{H}-\mathrm{CORT}$ levels in this region did exceed background, they were $<15 \%$ of those found in the $1 \mathrm{~mm}$ region of the cannula tip. In a preliminary study, we found the same distribution of radiolabeled CORT in animals killed $36 \mathrm{hr}$ following surgery. These findings indicate that throughout the $96 \mathrm{hr}$ period between CORT implant and stress testing, the steroid remained confined to the area of the implant. The amount of CORT within the 1-mmdiameter punch at the level of the cannula tip was estimated on the basis on the known specific activity of the radiolabeled steroid and averaged $16 \pm 4 \mathrm{ng}$.

Corticosteroid receptor binding. Representative Scatchard plots for ${ }^{3} \mathrm{H}$-aldosterone and ${ }^{3} \mathrm{H}$-RU 28362 binding in rat prefrontal cortex are presented in Figure $3 .{ }^{3} \mathrm{H}$-aldosterone (in the presence of an excess of cold RU 28362) bound with high affinity $\left(K_{d}=\right.$ $1.2 \pm 0.3 \mathrm{nM})$ in soluble fractions prepared from rat frontal 

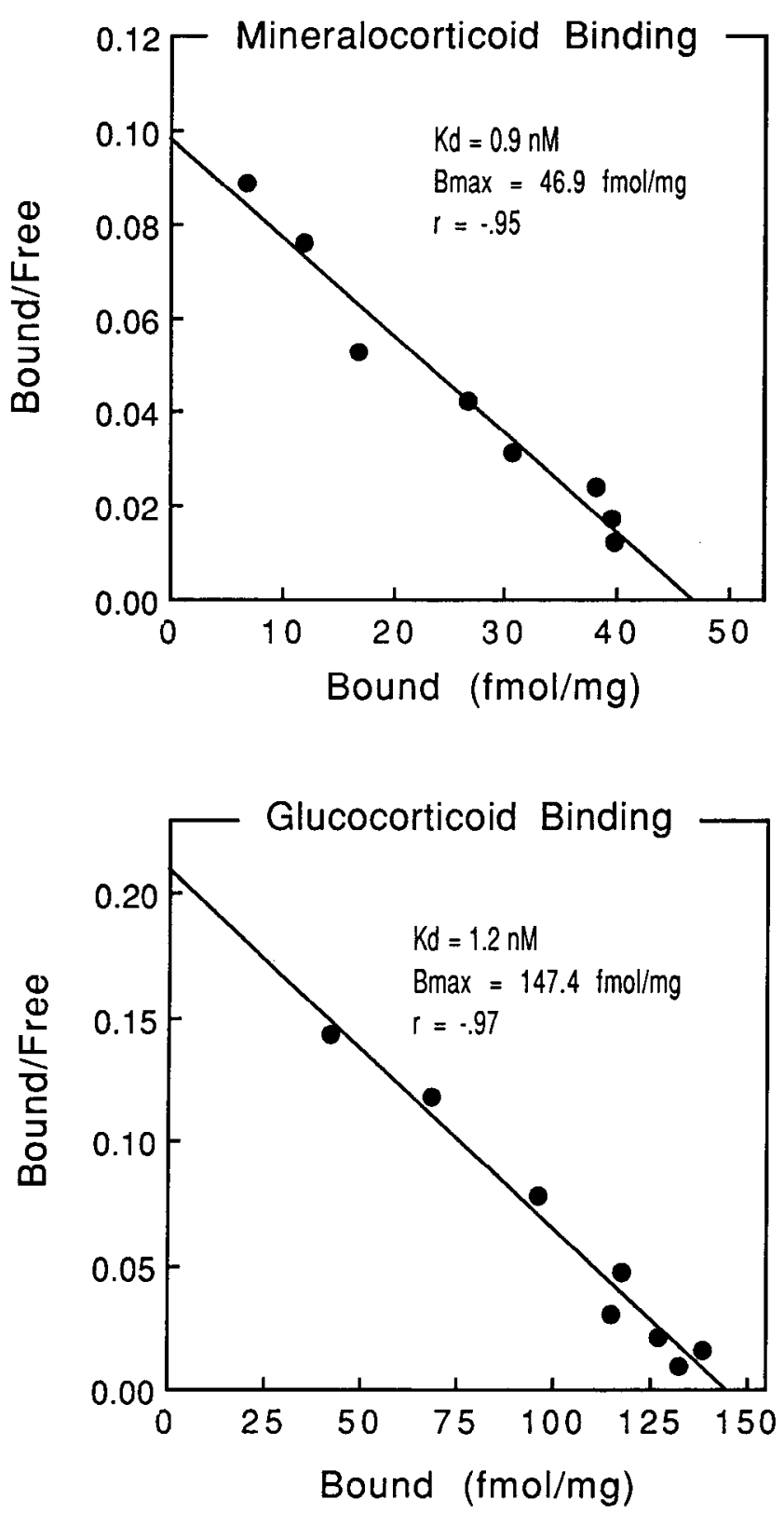

Figure 3. Representative Scatchard plots from saturation experiments using ${ }^{3} \mathrm{H}$-aldosterone (mineralocorticoid receptor binding) and ${ }^{3} \mathrm{H}-\mathrm{RU}$ 28362 (glucocorticoid receptor binding) with soluble fractions prepared from MpFC tissue.

cortex, with a modcratc capacity $\left(B_{\max }=42.9 \pm 3 \mathrm{fmol} / \mathrm{mg}\right.$ protein; $n=5$ ). Likewise, there was high-affinity RU 28362 binding $\left(K_{d}=0.8 \pm 0.1 \mathrm{nM}\right)$, with about four- to fivefold greater density of the glucocorticoid receptor sites $\left(B_{\max }=183.2 \pm 22\right.$ $\mathrm{fmol} / \mathrm{mg}$ protein; $n=5$ ). Prefrontal cortex lesions did not alter ${ }^{3} \mathrm{H}$-RU 28362 binding in the pituitary, hippocampus, hypothalamus, amygdala, or pituitary, or ${ }^{3} \mathrm{H}$-aldosterone binding in the hippocampus (data not shown). These findings suggest that there was no effect of the lesions on the sensitivity of these structures to circulating CORT.

Basal HPA activity. Plasma levels of CORT peaked in the early phase of the dark cycle (2000 hr). Basal plasma levels of CORT (see Fig. 4) did not differ significantly between lesion and sham-operated controls at any time point except for the

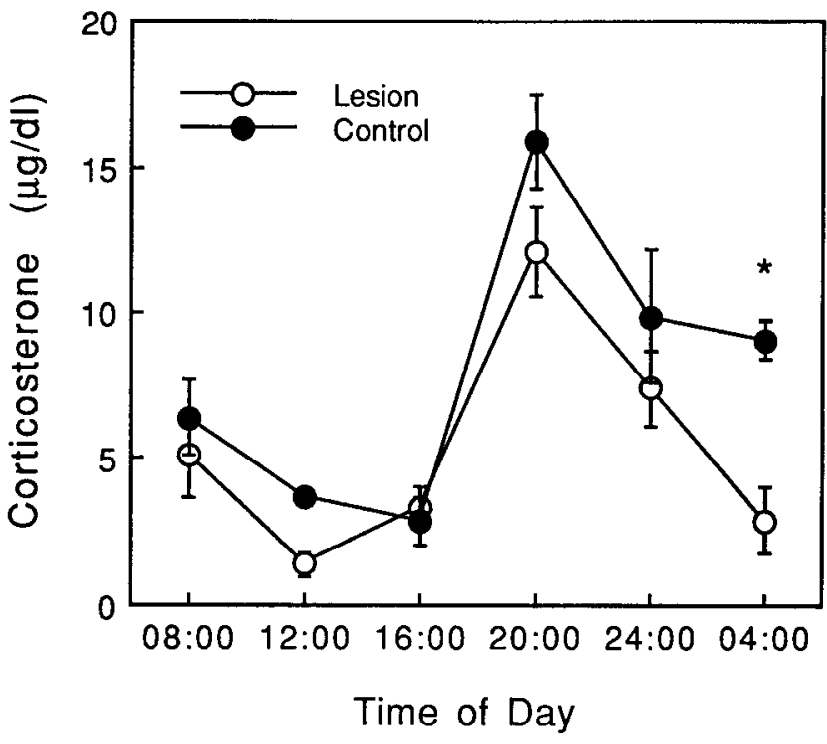

Figure 4. Mean \pm SEM basal CORT levels in animals with lesions of the MpFC and sham-operated controls ( $n=8$ per group) (lights off at $2000 \mathrm{hr}){ }^{*}, P<0.05$.

$0400 \mathrm{hr}$ CORT sample. Basal ACTH levels in lesion and control animals did not differ significantly in either the A.M. (43 \pm 5 vs $51 \pm 11 \mathrm{pg} / \mathrm{ml})$ or P.M. $(73 \pm 9$ vs $84 \pm 13 \mathrm{pg} / \mathrm{ml}$ ) sample. Moreover, prestress (basal) samples for either ACTH or CORT did not differ in any of the studies. Thus, there was little evidence from these studies for the regulation of basal HPA activity by the $\mathrm{MpFC}$.

Stress-induced HPA activity. Restraint stress produced a rapid and significant $(P<0.001)$ increase in plasma ACTH and CORT levels (see Fig. 5). Peak levels of ACTH and CORT during restraint did not differ between lesion and control animals. However, plasma ACTH levels were significantly $(P<0.05)$ higher in the lesioned animals at 20 and 40 min following the termination of restraint. Likewise, plasma CORT levels were significantly $(P<0.05)$ higher in the lesioned animals 30,60, and 120 min following restraint. Lesions of the $\mathrm{MpFC}$ had no effect on the clearance rate for CORT (see Fig. 7). These findings suggest that differences in plasma CORT levels reflect differences in hormone secretion rates and not in clearance from the plasma compartment.

Ether exposure provoked five- to eightfold increases in plasma ACTH and CORT (see Fig. 6). Elevations in both hormones were substantially higher following ether than those observed with restraint. However, at no time point did lesion and control animals differ significantly in plasma levels of cither ACTH or CORT.

CORT implants into the MpFC resulted in significantly $(P<$ $0.01)$ decreased levels of plasma $\mathrm{ACTH}$ in response to restraint stress (see Fig. 8, top). Peak CORT levels during restraint stress were also significantly reduced in the CORT-implant animals $(23.2 \pm 4$ vs $36.3 \pm 3 \mu \mathrm{g} / \mathrm{dl}, P<0.05)$. However, plasma ACTH responses to ether exposure were not significantly altered in CORT-implant animals compared with cholesterol-implanted controls (Fig. 9, top).

\section{Discussion}

The medial region of the rat prefrontal cortex contains both mineralocorticoid and glucocorticoid receptors for CORT (see 

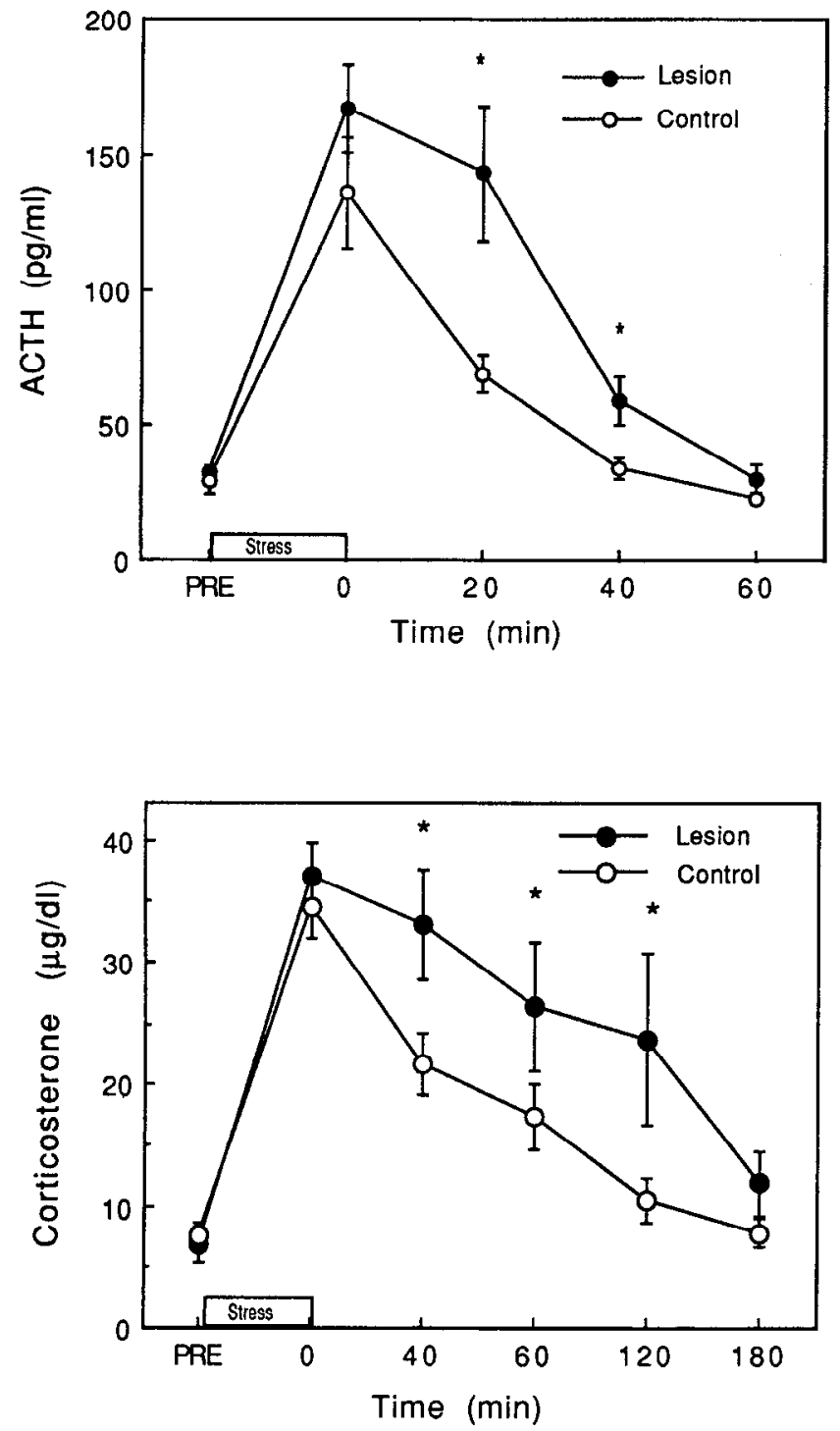

Figure 5. Mean \pm SEM plasma levels of ACTH (top) and CORT (bottom) in animals with lesions of the MpFC and sham-operated controls ( $n=8$ per group) prior to $(P R E)$, during $(0 \mathrm{~min})$, and at various time points following a 20 min period of restraint stress. ${ }^{*}, P<0.05$.

Fig. 3). These receptor sites share the binding properties (i.e., affinities for aldosterone and RU 28362) of mineralocorticoid and glucocorticoid receptors described elsewhere in the rat brain (see Reul and De Kloet, 1985; McEwen et al., 1986; Funder and Sheppard, 1987). The findings from these receptor binding assays are consistent with previous reports of ${ }^{3} \mathrm{H}$-CORT uptake in the rat cerebral cortex and the idea that the cortex is a corticosteroid target site (see McEwen et al., 1986).

Lesions of the cingulate gyrus region of the $\mathrm{MpFC}$ were associated with significantly increased plasma levels of both ACTH and CORT following restraint stress. CORT implants into this same region of the $\mathrm{MpFC}$ significantly reduccd plasma $\mathrm{ACTH}$ and CORT responses to restraint stress. These findings are consistent with the idea that the prefrontal cortex mediates an inhibitory effect of glucocorticoids on stress-induced HPA activity. Thus, the absence of a prefrontal cortex substrate resulted in an exaggerated HPA response to restraint, while an experimental condition that mimics elevated CORT levels locally
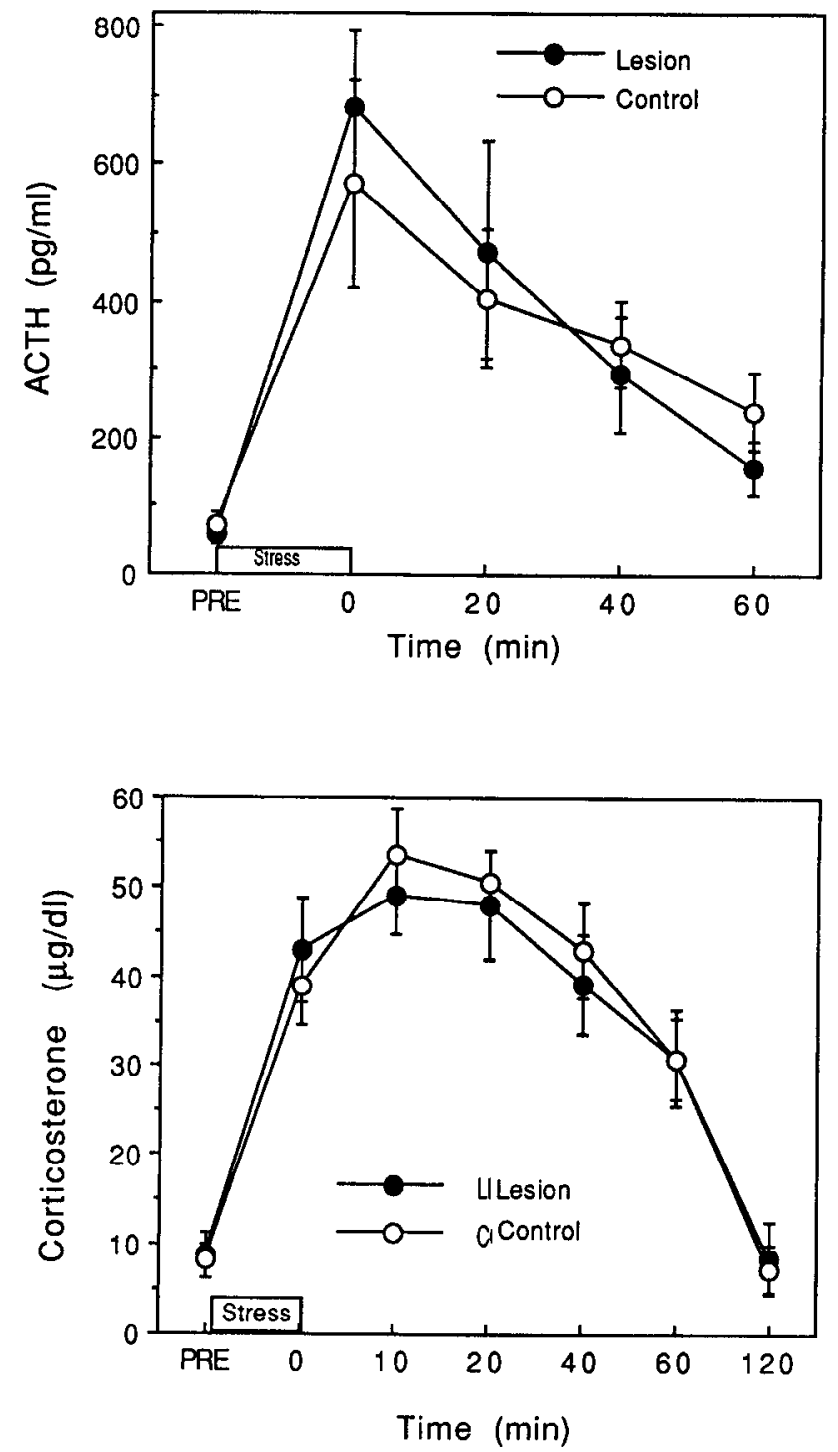

Figure 6. Mean \pm SEM plasma levels of ACTH (top) and CORT (bottom) levels in animals with lesions of the MpFC and sham-operated controls $(n=8$ per group) prior to $(P R E)$, during $(0 \mathrm{~min})$, and at various time points following a $2.5 \mathrm{~min}$ period of ether stress.

within the MpFC resulted in a decreased HPA response to restraint.

It is interesting to note that the lesion effect was observed only in the poststress period; there was no lesion effect on the peak levels of either ACTH or CORT. In contrast, there was a robust effect of CORT implants on the peak ACTH levels in response to restraint stress. This distinction suggests that the inhibitory influence of the prefrontal cortex is exerted only in the presence of elevated glucocorticoid levels. Thus, the lesion effect was apparent only once the increase in CORT levels had occurred (i.e., the stress period). However, it is also important to notc that thesc experiments were conducted during the midA.M. phase of the cycle, when plasma CORT levels are lowest. It is very likely that the elevated basal CORT levels observed in the PM phase of the cycle would be sufficient to reveal an effect of prefrontal cortex lesions on peak HPA responses to restraint stress.

These findings also suggest that the effects observed here likely 


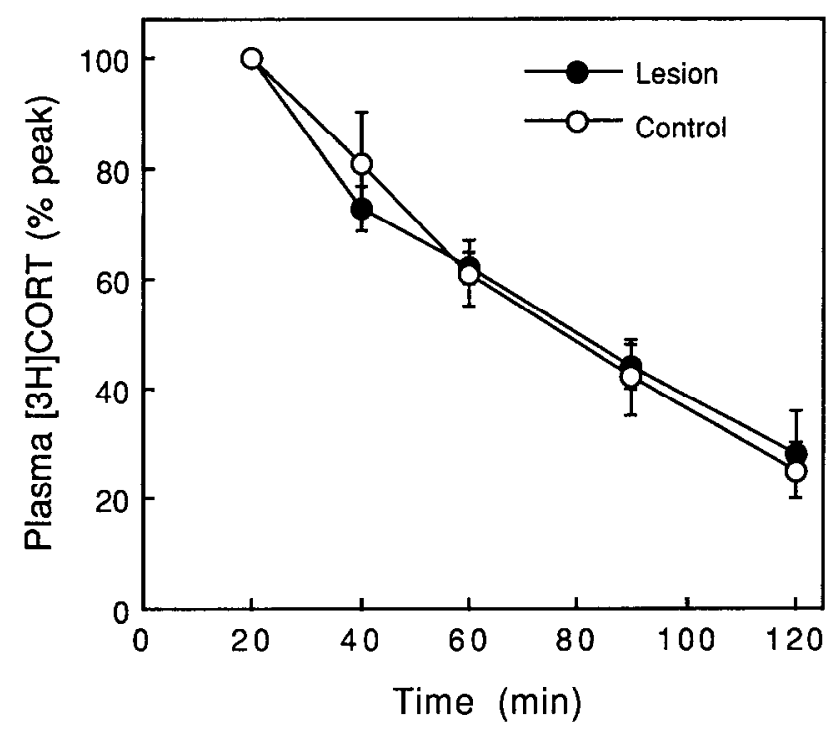

Figure 7. Mean \pm SEM plasma levels of ${ }^{3} \mathrm{H}$-CORT in animals with lesions of the MpFC and sham-operated controls ( $n=8$ per group) at various times following a bolus injection of radiolabeled CORT. The data are expressed as the percentage of the peak levels of radioactivity in plasma.

involve the glucocorticoid receptor population in the prefrontal cortex. The affinity of the mineralocorticoid receptor for CORT is about $5-10$-fold higher than that of the glucocorticoid receptor ( $\sim 0.5-1.0$ vs 2.0-10.0 nM; see Reul and De Kloet, 1985; McEwen et al., 1986; Funder and Sheppard, 1987). Under resting conditions in the A.M., circulating CORT levels are sufficient to occupy the majority of mineralocorticoid, but not glucocorticoid, receptor sites. As CORT levels rise, either in response to the circadian peak or to stress, there is an increase in glucocorticoid receptor occupancy, with little change in mineralocorticoid receptor occupancy (see Reul and De Kloet, 1985, 1987a,b; Meaney et al., 1988a). Akana et al. (1986, in press) have provided evidence for the idea that glucocorticoid negative-feedback in response to basal A.M. CORT levels is mediated via the mineralocorticoid receptor (see also Dallman et al., 1989). The fact that prefrontal cortex lesions did not affect the peak HPA response to restraint stress in the A.M. phase of the cycle is consistent with the idea that the glucocorticoid action at this site requires higher CORT levels, which would imply a primary role for the glucocorticoid receptor. Note, the CORT implants into the $\mathrm{MpFC}$, which mimic conditions of elevated CORT levels observed during stress or during the P.M. phase in CORT, did reduce the peak $A C T H$ response to restraint. This reasoning is also consistent with the finding that the density of glucocorticoid receptor sites in the prefrontal cortex was about four to five times higher than that for mineralocorticoid sites. By contrast, in the dorsal hippocampus, where both mineralocorticoid and glucocorticoid receptor sites are thought to mediate corticosteroid negative-feedback effects, there are comparable levels of the two receptors (e.g., Reul and De Kloet, 1985).

In contrast to the effects under restraint stress, neither the MpFC lesions nor CORT implants altered plasma ACTH or CORT responses to ether stress. The stress-dependent nature of the prefrontal cortex influence over HPA activity is a very interesting and novel finding. It is possible that the increased negative-feedback signal associated with CORT implants into the $\mathrm{MpFC}$ is sufficient to dampen the HPA response to mild
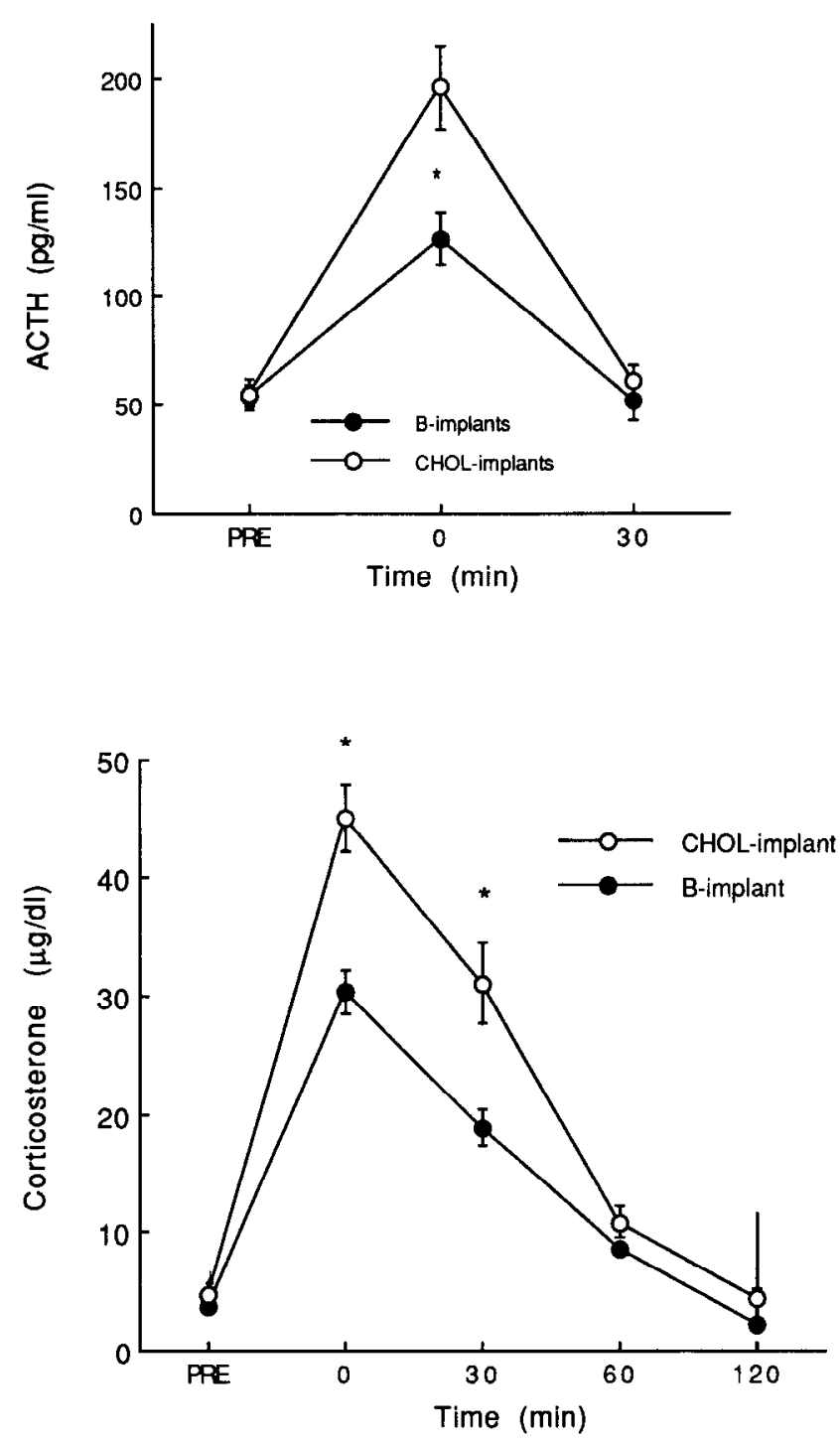

Figure 8. Mean \pm SEM plasma ACTH and CORT levels in animals with CORT or cholesterol (control) implants into the $\operatorname{MpFC}(n=8$ per group) prior to $(P R E)$, during $(0 \mathrm{~min})$, and following a $20 \mathrm{~min}$ period of restraint stress. ${ }^{*}, P<0.05$.

stressors, but is overridden by the intense excitatory drive associated with more severe forms of stress. The IIPA axis appears to respond in proportion to the intensity of the stressor (see Dallman et al., 1987) and plasma levels of both ACTH and CORT were appreciably higher following ether exposure than following restraint (see also Nakane et al., 1985). Hence, it seems reasonable (and intuitively appealing) to consider ether as the more severe stressor. If this is the case, then the differential effects of the MpFC manipulations may not necessarily reflect differences in the activity of this region under various forms of stress. Clearly, studies using a wider variety of stressors are required before we can resolve this question.

Alternatively, it is possible that the relevant frontal cortex projections impinge upon the hypothalamic-hypophysial signal involved in mediating ACTH release following restraint, but not ether. However, the results of several studies have failed to draw any clear distinction between the ACTH secretagogues involved in restraint and ether stress. Immunoneutralization of either CRH or AVP attenuates the increase in plasma ACTH 
associated with restraint or ether. It appears that the increased release of pituitary ACTH that occurs in response to both forms of stress involves CRH and AVP (Linton et al., 1985; Nakane et al., 1985). Thus, the specificity of the prefrontal cortex manipulations is probably not associated with effects on selected ACTH secretagogues.

A third possible explanation for the differential effects of prefrontal cortex manipulations on restraint versus ether stress concerns the nature of the relevant projections from the MpFC. It is possible that projections from the prefrontal cortex involve sites that mediate HPA responses to restraint, but not to ether. However, this is difficult to evaluate in the absence of a clear understanding of the CNS pathways that mediate the effects of these stimuli on the HPA axis. Nevertheless, there are known projections from the prefrontal cortex that are certainly could regulate HPA function and that may underlie the effects obscrved with restraint stress. Thus, an elevated CORT signal at the level of the MpFC could attenuate an HPA response to stress via inputs from this region to the PVN, presumably onto CRH/ AVP neurons, or to extrahypothalamic nuclei that comprise the excitatory neural drive over HPA function. There is anatomical evidence to support both possibilities. While the prefrontal cortex does not seem to project directly to the PVN, this region is a major source of afferents to the septum (see Swanson and Cowan, 1976), which in turn projects to the PVN (Sawchenko and Swanson, 1983). In addition, the prefrontal cortex also projects to regions such as the nucleus of the solitary tract (van der Kooy et al., 1984), which is a major source of catecholaminergic input into the PVN. Considering the central role of ascending catecholaminergic systems in activating the release of $\mathrm{ACTH}$ secretagogues from the PVN (e.g., Plotsky, 1987a,b), this projection might also be a source of regulation over HPA activity. In addition to the septum, there are other limbic projection sites from the prefrontal cortex, such as the amygdala (Saper, 1982), that are involved in autonomic function. Interestingly, lesions of the central nucleus of the amygdala alter HPA responses to restraint stress (Beaulieu et al., 1986, 1987).

Alternatively, the relevant projections from the prefrontal cortex might involve hypothalamic sites. In support of this idea, Feldman and Conforti (1985) reported that the effects of electrical stimulation of the frontal cortex on plasma CORT levels was blocked by lesions of the medial forebrain bundle (MFB). The frontal cortex has been shown to send projections directly into the MFB at the level of the lateral hypothalamus (Yamamoto and Shibata, 1975; Beckstead, 1979; Kita and Oomura, 1981). The MFB fibers course through the lateral hypothalamus and project into the PVN (see Sawchenko and Swanson, 1983). The MFB contains ascending catecholaminergic fibers that are known to bc involved in the stimulation of the HPA axis. Thus, Feldman and Conforti (1985) proposed that the relevant cortical input was at the level of the lateral hypothalamus and involved projections to the MFB. There are certainly numerous, potentially relevant projections from the prefrontal cortex, and there is no reason to consider these possibilities as mutually exclusive.

In a series of developmental studies we have shown that postnatal handling increases glucocorticoid receptor density (see Meaney et al., 1991, for a review) and glucocorticoid receptor mRNA levels (Larocque et al., 1992) in selected brain regions, notably the dorsal hippocampus and the frontal cortex. As adults, handled animals show reduced plasma ACTH and CORT responses to a wide variety of stressors (Levine, 1957, 1962; Meaney et al., 1988b, 1989) and reduced CRH and AVP content in
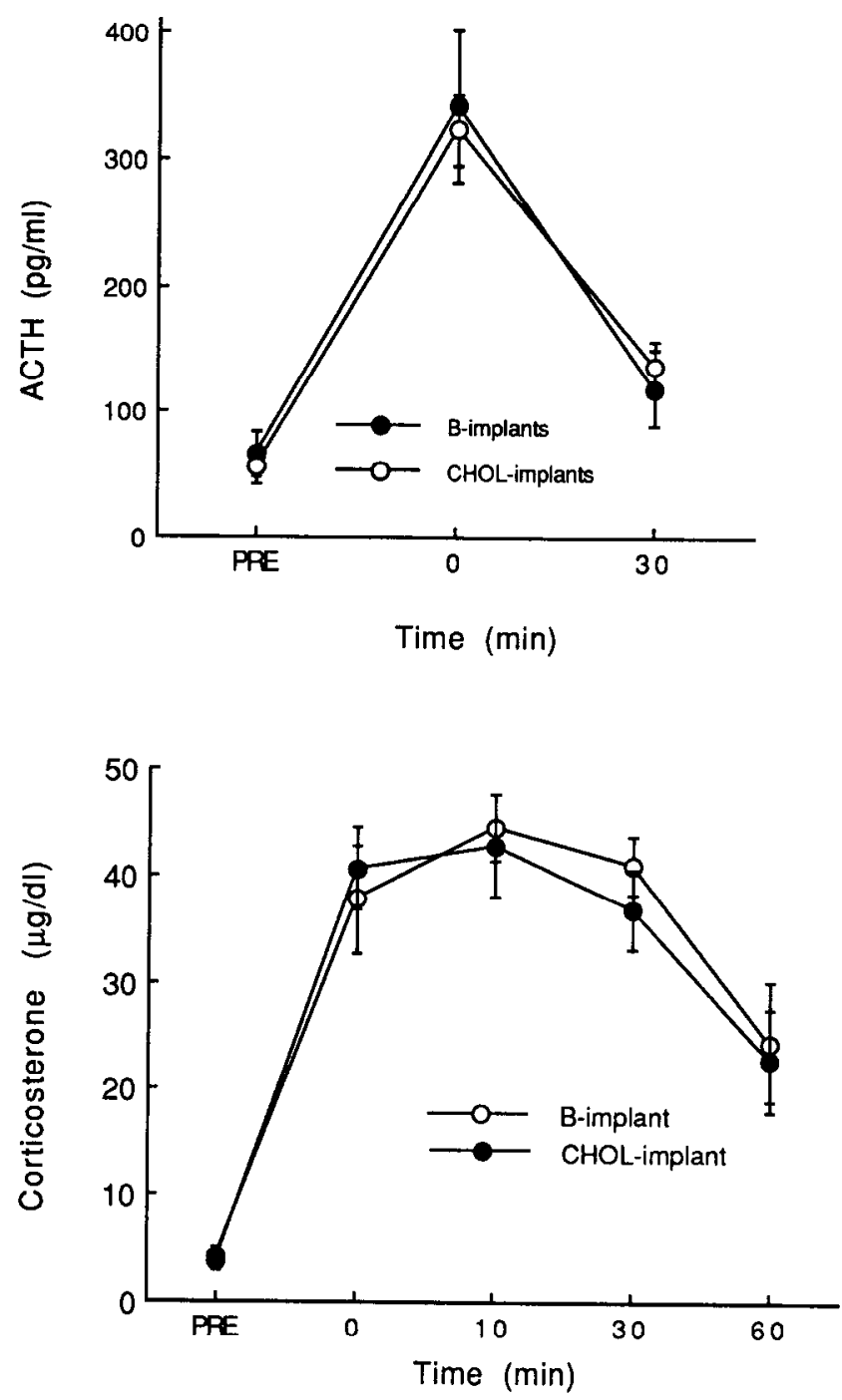

Figure 9. Mean \pm SEM plasma ACTH and CORT levels in animals with CORT or cholesterol (control) implants into the $\mathrm{MpFC}(n=8$ per group) prior to $(P R E)$, during (0 min), and following a $2.5 \mathrm{~min}$ period of ether stress. ${ }^{*}, P<0.05$.

the median eminence and hypothalamic CRH mRNA levels (Viau et al., 1993; M. J. Meaney and P. M. Plotsky, unpublished observations). While the handling effect is known to involve changes at the level of the hippocampus, the present data suggest that changes in glucocorticoid receptor density in the frontal cortex might also be of importance for the effect of handling on HPA function. Thus, handling increases glucocorticoid receptor density in the frontal cortex, which could then result in increased sensitivity to elevated CORT and in enhanced inhibition of plasma ACTH and CORT responses to stress.

The role of the prefrontal cortex in the regulation of HPA function is of considerable interest and provides a mechanism whereby cortical activity might regulate rudimentary endocrine responses to conditions that threaten homeostasis. There is now considerable evidence for the importance of the hippocampus in the regulation of HPA function and, in particular, as a critical target site for the negative-feedback effects of glucocorticoids. Interestingly, the hippocampus and prefrontal cortex share a rather rich history in neurology as brain regions involved in the 
inhibition of autonomic and cmotional responses to fear-inducing stimuli (Cannon, 1929; Papez, 1937; MacLean, 1949; see LeDoux, 1987, for a review). Thus, considering the high level of integration of defensive responses to stress, it is not surprising that these regions should emerge as critical sites in the regulation of endocrine responses to stress.

\section{References}

Akana SF, Cascio CS, Du J-Z, Levin N, Dallman MF (1986) Reset of feedback in the adrenocortical system: an apparent shift in sensitivity of adrenocorticotropin to inhibition by corticosterone between morning and evening. Endocrinology 119:2325-2332.

Akana SF, Scribner KA, Bradbury MJ, Strack AM, Walker C-D, Dallman MF (in press) Feedback sensitivity of the rat hypothalamopituitary-adrenal axis and its capacity to adjust to exogenous corticosterone. Endocrinology, in press.

Antoni FA (1986) Hypothalamic control of ACTH secretion: advances since the discovery of 41 -residue corticotropin-releasing factor. Endocr Rev 7:351-370.

Beaulieu S, Di Paolo T, Barden N (1986) Control of ACTH secretion by the central nucleus of the amygdala: implication of the serotoninergic system and its relevance to the glucocorticoid delayed feedback mechanism. Neuroendocrinology 44:247-254.

Beaulieu S, Di Paolo T, Cote J, Barden N (1987) Participation of the central nucleus of the amygdala in the response of adrenocorticotropin secretion to immobilization stress: opposing roles of the noradrenergic and dopaminergic systems. Neuroendocrinology 45:37-46.

Beckstead RM (1979) Autoradiographic examination of corticortical and subcortical projections of the mediodorsal-projection (prefrontal) cortex in the rat. J Comp Neurol 184:43-62.

Bradbury MJ, Akana SF, Cascio CS, Levin N, Jacobson L, Dallman MF (1991) Regulation of basal ACTH secretion by corticosterone is mediated by both type I (MR) and type II (GR) receptors in rat brain. J Steroid Biochem Mol Biol 40:133-142.

Bradford M (1976) A rapid and sensitive method for quantitation of microgram quantities of protein utilizing the principle of protein-dye binding. Anal Biochem 72:248-254.

Cannon WB (1927) The James-Lang theory of emotions: a critical examination and an alternative theory. Am J Psychol 39:106-124.

Coirini H, Magarinos AM, DeNicola AF, Rainbow TC, McEwen BS (1985) Further studies of brain aldosterone binding sites employing new mineralocorticoid and glucocorticoid receptor markers in vitro. Brain Res 361:212-217.

Dallman MF, Akana S, Cascio CS, Darlington DN, Jacobson L, Levin N (1987) Regulation of ACTH secretion: variations on a theme of B. Rec Prog Horm Res 43:113-173.

Dallman MF, Levin N, Cascio CS, Akana SF, Jacobson L, Kuhn RW (1989) Pharmacological evidence that the inhibition of diurnal corticotropin secretion by corticosteroids is mediated via type I, corticosterone-preferring receptors. Endocrinology 124:2844-2850.

Dallman MF, Akana SF, Scribner KA, Bradbury MJ, Walker C-D, Strack AM, Cascio CS (in press) Stress, feedback and facilitation in the hypothalamo-pituitary-adrenal axis. J Neuroendocrinol, in press.

Feldman S, Conforti N (1985) Modifications of adrenocortical responses following frontal cortex stimulation in rats with hypothalamic deafferentations and medial forebrain bundle lesions. Neuroscience 15:1045-1047.

Funder JW, Sheppard K (1987) Adrenocortical steroids and the brain. Annu Rev Physiol 49:397-412.

Gibbs DM (1986) Vasopressin and oxytocin: hypothalamic modulators of the stress response. Psychoneuroendocrinology 11:131-140.

Gray JA (1982) The neuropsychology of anxiety. New York: Oxford UP.

Herman JP, Schafer MK-H, Young EA, Thompson R, Douglass J, Akil $\mathrm{H}$, Watson SJ (1989) Evidence for hippocampal regulation of neuroendocrine neurons of the hypothalamo-pituitary-adrenocortical axis. J Neurosci 9:3072-3082.

Jacobson L, Sapolsky RM (1991) The role of the hippocampus in feedback regulation of the hypothalamic-pituitary-adrenal axis. Endocr Rev 12:118-134.

Kalimi M, Hubbard JR (1983) Development of an exchange assay for cytosolic glucocorticoid receptors using the synergistic effects of molybdate plus dithiothreitol. Endocrinology 113:1161-1163.
Kita H, Oomura Y (1981) Reciprocal connections between lateral hypothalamus and the frontal cortex in the rat: electrophysiological and anatomical observations. Brain Res 213:1-16.

Krey LC, Lu K, Butler W, Hotchkiss J, Piva F, Knobil E (1975) Surgical disconnections of the medial basal hypothalamus and pituitary function in the rhesus monkey. II. GH and cortisol secretion, Endocrinology 96:1088-1096.

LaRocque S, O'Donnell D, Seckl JR, Meaney MJ (1992) Postnatal handling increases hippocampal glucocorticoid, but not mineralocorticoid receptor mRNA levels in the rat. Soc Neurosci Abstr 18: 479

LeDoux JE (1987) Emotion. In: Handbook of physiology, Vol 1, The nervous system (Mountcastle VB, Plum F, Geiger SR, eds), pp 419459. Bethesda, MD: American Physiological Society.

Levine S (1957) Infantile experience and resistance to physiological stress. Science 126:405-406.

Levine S (1962) Plasma-free corticosteroid response to electric shock in rats stimulated in infancy. Science 135:795-796.

Linton EA, Tilders FJH, Hodgkinson S, Berkenbosch F, Vermes I, Lowry PJ (1985) Stress-induced secretion of adrenocorticotropin in rats is inhibited by antisera to corticotropin-releasing factor and vasopressin. Endocrinology 116:966-970.

MacLean PD (1949) Psychosomatic disease and the visceral brain: recent developments bearing on the Papez theory of emotion. Psychosom Med 11:338-353.

McFwen BS, De Kloet ER, Rostene WH (1986) Adrenal steroid receptors and actions in the nervous system. Physiol Rev 66:11211150.

Meaney MJ, Aitken DH (1985) $\left[{ }^{3} \mathrm{H}\right]$ dcxamcthasone binding in rat frontal cortex. Brain Res 328:176-180.

Meaney MJ, McEwen BS (1986) Testosterone implants into the amygdala during the neonatal period masculinize the social play of juvenile female rats. Brain Res 398:324-328.

Meaney MJ, Viau V, Bhatnagar S, Aitken DH (1988a) Occupancy and translocation of hippocampal glucocorticoid receptors during and following stress. Brain Res 445:198-203.

Meaney MJ, Aitken DH, Bhatnagar S, Van Berkel C, Sapolsky RM (1988b) Postnatal handling attenuates neuroendocrine, anatomical and cognitive impairments related to the aged hippocampus. Science 238:766-768.

Meaney MJ, Aitken DH, Sharma S, Viau V, Sarrieau A (1989) Postnatal handling increases hippocampal glucocorticoid receptors and enhances adrenocortical negative-feedback efficacy in the rat. Neuroendocrinology 50:597-604.

Meaney, MJ, Mitchell JB, Bhatnagar S, Iny LJ, Bodnoff SR, Viau V, Sarrieau A (1991) The effects of neonatal handling on the development of the adrenocortical stress response: implications for neuropathology and cognitive deficits in later life. Psychoneuroendocrinology 16:87-105.

Nakane T, Aughya T, Kanie N, Hollander CS (1985) Evidence for the role of endogenous corticotropin-releasing factor in cold, ether, immobilization, and a traumatic stress. Proc Natl Acad Sci USA 82: 1247-1251.

Palkovits M, Brownstein MJ (1988) Maps and guide to microdissection of the rat brain. New York: Elsevier.

Papez JW (1937) A proposed mechanism of emotion. Arch Neurol Psychiatry 79:217-224.

Paxinos G, Watson D (1982) The rat brain in stereotaxic coordinates. New York: Academic.

Philibert D, Moguilewsky M (1983) RU 28362, a useful tool for the characterization of glucocorticoid and mineralocorticoid receptors. Endocr Soc Abstr 9:335.

Plotsky PM (1987a) Regulation of hypophysiotropic factors mediating ACTH secretion. Ann NY Acad Sci 512:205-217.

Plotsky PM (1987h) Facilitation of irCRF secretion into the hypophysial-portal circulation following activation of catecholaminergic pathways or central norepinephrine injection. Endocrinology 121: 924-930

Plotsky PM, Meaney MJ (1993) Postnatal handling alters hypothalamic CRF mRNA, synthesis, and release. Mol Brain Res 18:195200.

Ratka A, Sutanto W, Bloemers M, De Kloet ER (1989) On the role of brain mineralocorticoid (type I) and glucocorticoid (type II) receptors in neuroendocrine regulation. Neuroendocrinology 50:117-123.

Reul JMHM, De Kloet ER (1985) Two receptor systems for corti- 
costerone in rat brain: microdistribution and differential occupation, Endocrinology 117:2505-2511.

Reul JMHM, van den Bosch FR, De Kloet ER (1987a) Relative occupation of typc-I and typc-II corticostcroid reccptors in rat brain following stress and dexamethasone treatment: functional implications. J Endocrinol 115:459-467.

Reul J, van den Bosch FR, De Kloet ER (1987b) Differential response of type I and type II corticosteroid receptors to changes in plasma steroid levels and circadian rhythmicity. Neuroendocrinology 45:407412.

Rivier C, Plotsky PM (1986) Mediation by corticotropin-releasing factor of adenohypophysial hormone secretion. Annu Rev Physiol 48:475-489.

Rivier C, Brownstein M, Spiess J, Rivier J, Vale W (1982) In vivo corticotropin-releasing factor-induced secretion of adrenocorticotropin, $\beta$-endorphin, and corticosterone. Endocrinology 110:272-278.

Saper CB (1982) Convergence of autonomic and limbic connections in the insular cortex of the rat. J Comp Neurol 210:163-173.

Sapolsky RM, Krey LC, McEwen BS (1984) Glucocorticoid-sensitive hippocampal neurons are involved in terminating the adrenocortical stress response. Proc Natl Acad Sci USA 81:6174-6177.

Sapolsky RM, Krey LC, McEwen BS (1986) The neuroendocrinology of stress and aging: the glucocorticoid cascade hypothesis. Endocr Rev 7:284-301.

Sarrieau A, Dussaillant M, Sapolsky RM, Aitken DH, Olivier A, Lal S, Rostene WH, Quirion R, Meaney MJ (1988) Glucocorticoid binding sites in human temporal cortex. Brain Res 442:159-163.
Sawchenko PF, Swanson LW (1983) The organization of forebrain afferents to the paraventricular and supraoptic nuclei of the rat. $J$ Comp Neurol 218:121-144.

Scatchard G (1949) The attraction of proteins for small molcculcs and ions. Ann NY Acad Sci 51:660-672.

Swanson LW, Cowan MW (1976) Autoradiographic studies of the development and connections of the septal area in the rat. In: The septal nuclei (De France JF, ed), pp 37-64. New York: Plenum.

Swanson LW, Sawchenko PE, Lind RW, Rho JH (1987) The CRH motoneuron: differential peptide regulation in neurons with possible synaptic, paracrine, and endocrine outputs. Ann NY Acad Sci 512: 12-23.

van der Kooy D, Koda LY, McGinty M, Gerfen CR, Bloom FE (1984) The organization of projections from the cortex, amygdala, and hypothalamus to the nucleus of the solitary tract in rat. J Comp Neurol 224:1-24.

Viau V, Sharma S, Plotsky PM, Meaney MJ (1993) Increased plasma ACTH responses to stress in nonhandled compared with handled rats require basal levels of corticosterone and are associated with increased levels of ACTH secretagogues in the median eminence. J Neurosci 13:1097-1106.

Yamamoto T, Shibata Y (1975) Direct fiber connections between the frontal cortex and the hypothalamus in the rat: an electron microscopic study. Pharmacol Biochem Behav 3[Suppl 1]:15-22. 